\title{
SELECTED ASPECTS OF THE INTERNET OF THINGS DURING GLOBALIZATION
}

\author{
Martina Kovacikova ${ }^{1}$, Katarina Repkova Stofkova ${ }^{2}$
}

\begin{abstract}
Continuous technological progress makes it possible to use the Internet of Things (IoT) in broader dimensions. Digitization, computerization, and innovation are now key factors for businesses and countries to achieve added value and make progress in competitiveness and attractiveness. These are also optimal conditions for the application of IoT. This study aims to show the status of the implementation of IoT in neighboring countries — the Slovak Republic and the Czech Republic - compared to the United Kingdom, which is in the lead. Similarly, the goal was to compare the areas of digitization and informatization to the Networked Readiness Index (NRI), the Digital Economy and Society Index (DESI), and the Digital Transformation Scoreboards (DTS). Material support for this paper was garnered from the relevant literature. The theoretical basis for issues related to IoT was presented after analyzing secondary sources to determine the current state of the industry and the level of digitization. The those indexes were compared using data from Slovakia, the Czech Republic, and the UK. The UK is among the leaders in the field of IoT. The resulting data are presented graphically. Slovak companies that operate mainly in the industrial sector are beginning to discover and implement IoT. More and more cities are adopting this technology. The situation in the UK is already quite far along. During the evaluation of the NRI, DESI, and DTS, Slovakia was ranked lowest, the Czech Republic was ranked slightly higher, and the UK was rated the highest. Comparison of the digitization of the economy and society, and the deployment and use of ICT highlight the need for further development of these areas in the Slovak and Czech republics.
\end{abstract}

JEL Classification Numbers: O32, P42, F15, DOI: https://doi.org/10.12955/peb.v1.27

Keywords: Internet of Things, digitalization, globalization

\section{Introduction}

The Internet of Things (IoT) offers extensive opportunities, especially for countries whose economies are heavily dependent on industry. Therefore, it is necessary for developing countries to focus on the implementation of new legislation, infrastructure, promotion and investments in science and research. That will ensure adequate conditions for the implementation of new technologies, which are a prerequisite for a country's economic growth. In the context of IoT, this paper deals with the following areas: specification of theoretical bases for the issue, analysis of secondary sources to determine the current state of the industry in the Slovak Republic and selected countries, and analysis of the position of the Slovak Republic and selected states in NRI, DESI, and DTS.

For comparison, the Czech Republic was chosen because in the past it formed a common state with the Slovak Republic, and the United Kingdom, which is among the leaders in the IoT industry. This study aims to show the status of implementation of IoT in neighboring countries, such as the Slovak Republic and the Czech Republic, compared to the United Kingdom, which is the leader among those three. Similarly, another goal was to compare the area of digitization, informatization by comparing them to the NRI and DESI index and DTS.

\section{Methodology and Methods}

Like the classic Internet, the Internet of Things is quickly becoming an essential part of life, business and the government. Practical examples of the use of IoT are, e.g., position monitoring, measurement of various quantities, monitoring of occupancy of parking spaces, monitoring of the health conditions of patients, the conservation of energy, and others. The most common applications of IoT technologies include agriculture, energy conservation, security, and smart city solutions. Smart City is a designation for a city that includes information and communication technologies to improve the quality of life, performance, and especially the operational efficiency of urban services to reduce resource consumption, waste, and overall costs. The main objective of an intelligent city is to improve the quality of life for its citizens by implementing smart, modern technology and thus contribute to the well-being of its citizens. (Chcemsmartmesto 2019)

The informatization process means the implementation of information and communication technologies in multiple areas of the everyday life of citizens to improve their quality of life. (Gasova, 2017) Digitization, computerization, and innovation are currently key factors for businesses and for individual

\footnotetext{
${ }^{1}$ University of Zilina, Faculty of operation and Economics of Transport and Communication, Department of Communication, Slovakia, martina.kovacikova@fpedas.uniza.sk

${ }^{2}$ University of Zilina, Faculty of operation and Economics of Transport and Communication, Department of Communication, Slovakia, katarina.stofkova@fpedas.uniza.sk
} 
countries in creating added value and advancing competitiveness and attractiveness. The NRI index of selected countries was chosen to create a comparison that assesses the readiness of countries. The ICT and DESI indexes were used to measure the digital progress of each country; whereas, the Digital Transformation Table is used to provide data and analysis on the introduction of digital technologies among the most progressive enterprises in each country of the European Union. The IoT is not just about digitization, its presence is essential for the implementation of intelligent manufacturing systems and services. The supporting data for this paper were derived from the relevant literature, such as the official sources of the European Union, its several states, cities, and organizations as listed among the references attached hereto. Issues regarding the IoT were presented using a theoretical basis while analyzing multiple secondary sources to determine the current state of industry and the level of digitization. The indexes of Slovakia and the Czech Republic were compared with the index of the UK, which is among the leaders in the field of IoT. The findings that resulted from the secondary survey are presented graphically.

\section{Internet of Things}

\subsection{Defining the term Internet of Things}

In contrast to conventional industrial automation and machine-to-machine operating models, the IoT differentiates itself by making humans an integral part of its overall ecosystem. (Andreev, S. et al., 2019) The IoT is a modern day technological phenomenon and requires a clear description that defines it use, explains its communication abilities, and discretely identify its underlying technologies. The most apt definitions include those formulated by reputable companies such as Gartner, Accenture, and the Bankinter Foundation of Innovation. According to the global research firm Gartner, the IoT may be defined as "a network of physical objects that incorporates embedded technologies for communication and perception, or affects their internal states or external environment." (Gartner, 2019)

Perhaps the most comprehensive definition is this one: "The Internet of Things (IoT) is an interconnected network of physical devices which range from simple sensors to complex smartphones. These smart objects are able to collect and share information via the internet with other smart objects or cloud-based applications." (Digital Goals, 2020)

Each company explains the term in a slightly different way, but the essence among them is that the IoT allows interconnection and communication between objects through the Internet, using a wide range of technologies. Continuous technological advancements will enable companies to use the IoT along more diversified avenues. The Internet of Things consists of two main areas, the Industrial IoT, which is used in industries to govern resource efficiency by lowering operating costs or interconnecting technology. The other is the Consumer IoT, which focuses on enhancing the daily lives of consumers, for example through home automation or wearable electronics to augment the user experience. (Pohanka, 2019)

\subsection{Technology}

The Internet of Things comprises a wide range of technologies that incorporate autonomous operation and/or communication between objects or persons. Communication technologies include Wi-Fi, Bluetooth, BLE, LoRa, Sigfox, and NB-IoT. These are wireless technologies that promote efficiency, mobility, and high adaptability to the environment. All objects of the IoT must be clearly identifiable using the IPv6 identification technology. Given the forecasts of the analysts some years ago, who expect $2-5$ billion devices to be connected by 2020, the address space of the previous IPv4 protocol would not be enough. (Wong, 2012) Objects of IoT generate huge amounts of data, so-called Big Data, that need to be stored, processed, and shared. Big data can be defined as large volumes of structured or unstructured data, usually in the size of petabytes $\left(10^{15}\right.$ bytes $)$ or more, which are enormously diverse and exceed the capabilities of current database technologies. Special procedures and software tools are required to process the overabundance of data. An analysis of Big Data underscores the need to optimize data processing protocols because speedy processing and analyzing are essential parts of the IoT system. (Technopedia, 2019; NetApp, 2019) Cloud computing enables data storage and data access via cloudbased applications almost anytime and from almost anywhere.

\subsection{The implementation phase of the Internet of Things}

The implementation of the Internet of Things in a company can be categorized into several phases. Based on its experience, Bsquare has divided the implementation of the IoT into five progressive phases. Bsquare contends companies do not have to achieve every stage of the IoT implementation because it 
depends on their business goals and desired results. According to its website, the implementation of the IoT can be divided into the following phases: device connectivity and data transfer; real-time monitoring; data analysis; automation; and increased onboard intelligence. (Yost, 2019) The digital transformation of businesses and society affects traditional professions. The European Union calls for strengthening digital skills, updating curricula, and training. Retraining is also directed at sectors that are not primarily based on the use of ICT (Stofkova \& Hraskova, 2017; Soltes, et al., 2016). The implementation of modern technology, techniques, and management methodologies specific to Industry 4.0 should cover the entire production process as well as management processes. (Grabowska, 2020)

\section{Internet of Things in Selected Countries}

\subsection{Internet of Things in the Slovak Republic}

The Slovak Republic ranks among the countries heavily dependent on industry. Industry is largely influenced by the development of engineering and automotive production. Together with the electrotechnical and metallurgical industries, these are the largest drivers of growth in industrial production in a given country. Slovak companies that operate mainly in the industrial sector are beginning to discover and implement the IoT in various industrial enterprises. Also, some Slovak cities are starting to exploit the potential of the IoT. The cities of Bratislava, Trnava, Hlohovec, Trencin, Banska Bystrica, Dolny Kubin, and Presov are involved in the initiative "I Want a Smart City", which represents the building of so-called smart cities. (Chcemsmartmesto, 2019) Nitra is a leader in the niche of transforming municipalities into smart cities within the Slovak Republic and has created its own project called Nitra Smart City. The project aims to install more than 10,000 sensors, mainly for energy conservation and management in smart buildings. It will also enable the purchase of electric buses and the construction of operating facilities, a bicycle sharing service, the construction of public transport stations with benches that will enable internet connection. The aim is also the reconstruction of public lighting, providing a camera system, linking parking in the city with a mobile application, and providing sensor-equipped containers for municipal waste. (Nitra Smart City, 2019)

Internet of Things solutions are used not only in companies and cities but also in homes where the Internet of Things is integrated into common equipment, appliances, and energy monitoring and control devices. In 2018, IoT devices targeting households only generated sales of $€ 26.8$ million within the Slovak Republic, with smart devices accounting for the largest share of these revenues, €6.9 million. (IndexMundi, 2019; Statista, 2019; Statista, 2020)

\subsection{Internet of Things in the Czech Republic}

Industrial production is the main component of the economy of the Czech Republic, comprising a major share of the country's total production and foreign trade. The main branches of the Czech industry include mechanical engineering, automotive production, food processing, metallurgy, and chemical production. (MPaO ČR, 2020; Statista, 2020)

Cities in the Czech Republic are not lagging in the implementation of the IoT when compared to industrial enterprises. Smart cities include large and small municipalities. The first intelligent city in the Czech Republic is considered to be the town of Písek, followed by Prague, Brno, Ostrava, Pardubice, Pilsen, Zlín, and Kolín. Cities within the Czech Republic have grasped the concept of Smart Cities, which is primarily a guide on how to approach smart cities. The authors of the concept focused mainly on the description of the attributes of an intelligent city and the key areas of the use of information and communication technologies, such as transport and energy. (Barta, 2015)

As the capital of the Czech Republic, Prague is one of the leading municipalities creating a smart city. The concept of a Smart Prague is being promoted and six key areas have been designated for modern technologies that will have the most significant positive impacts on the life of its citizens. The first area is the Mobility of the Future, which is designed to ensure more comfortable and smoother transportation through intelligent control, parking, and payment. Other areas are intelligent buildings, energy, and people and the urban environment. Another area envisions a waste-free city that should treat and utilize municipal waste and non-potable water.

The segment of attractive tourism is intended to offer visitors to Prague many attractions, while they will be able to use a Tourist Card to move around the city and enter the main attractions. The final area is the collection, storage, processing and access to data, which is the core of the concept. (SmartPrague 2019) Within the Czech Republic, the IoT is also used by households. In 2018, the market share that 
focused on the application of IoT solutions in households reached $€ 58.8$ million in the Czech Republic. Intelligent devices accounted for the most revenue, with sales of $€ 18.4$ million. (Statista, 2019)

\subsection{The Internet of Things in the United Kingdom}

Industrial production in the United Kingdom is declining and the service sector is now at the lead, with the country achieving moderate economic growth. Nevertheless, industry in the UK maintains an important position. The UK's major industries include mechanical engineering, especially in the automotive and aircraft industries, the food, pharmaceutical, petrochemical, as well as the IT industry. These are among the country's fastest-growing industries. (Statista, 2020; MZV SR, 2019)

The presence of the Internet of Things is growing rapidly in the UK not only among businesses but also among municipalities and individuals. The country has a Future Cities Catapult, which is supported by the UK government and focuses on smart city developments. The center covers several programs, one of which is the Future Cities demonstrator. The program aims to test different technologies and practices in multiple cities in the United Kingdom, to evaluate them, and to support best practices through a subsidy program. Major smart cities include Bristol, London, Manchester, Birmingham, Leeds, Glasgow, Nottingham, Edinburgh, and Belfast. (Hurst, 2018)

London, the capital of the United Kingdom, is one of the most progressive cities worldwide in incorporating smart city technology. The city has initiated its Smarter London Together project, which aims to become the best intelligent city in the world. The project defines five main objectives and seven other strategies that focus on transport, environment, health, smart housing, culture, economic development, and London's long-term development plan. The first major objective is Multiple UserDesigned Services, which aims to encourage citizens to engage in innovative activities. The second is to develop a strategy for urban data to strengthen cybersecurity, increase transparency, innovation, and the amount of data shared for the benefit of Londoners. Another goal is "Smart Streets and Connections" to expand the public Wi-Fi network, support the next generation of smart infrastructure and unify standards with smart technologies. The next aim is to Improve Digital Skills to develop the digital skills of workers and citizens. The last goal is to improve collaboration among other cities and to share best practices for the optimal implementation of the IoT. (Mayor of London, 2019)

The Internet of Things is also used by citizens to create a smart home. In the United Kingdom, in 2018, the IoT solutions market targeted households and generated sales of $€ 2.6$ billion, most of which was controlled and connected, with sales of €528.2 million. (Statista, 2019)

\section{Comparison of selected countries in the digitization of the economy and society, and the deployment and use of ICT}

\subsection{Comparisons using the NRI index}

The NRI measures how well countries are prepared for the future and how they use information and communication technologies to increase competitiveness and well-being. The ongoing Fourth Industrial Revolution is a wholesale transition to a completely new infrastructure that combines digital, biological, physical, and ICT technologies into new and powerful combinations. The compilation of the rankings of countries using the NRI index is based on a wealth of data that is collected from international organizations. The NRI examines four basic areas, which are the political and regulatory environment, the business and innovation environment, preparedness, which includes infrastructure and accessibility, and widespread use by individuals, businesses, and government. (Breene, 2016) The following figure shows the NRIs for the Slovak Republic, the Czech Republic, and the United Kingdom. (Figure 1)

The Slovak Republic ranked 47th in the NRI, with the best rating for use by individuals, businesses, and governments, and the lowest in selected countries. The Czech Republic ranked 36th, with its highest rating for readiness assessment. In selected countries, the UK ranked best, ranking eighth. The UK's highest rating was for the environment. Singapore, Finland, and Sweden topped the NRI 2016 rankings, while Haiti, Burundi, and Chad were the worst.

\subsection{Comparison in the Digital Economy and Society Index}

The Digital Economy and Society Index is a composite index that summarizes relevant indicators on the digital performance of the individual Member States of the European Union and monitors their development in the field of digital competitiveness. Digital progress is measured by DESI in five areas: 
connectivity (speed, price, broadband), internet use (communication, online transactions), digital technology integration (business digitization, e-commerce) and digital public services (eGovernment).

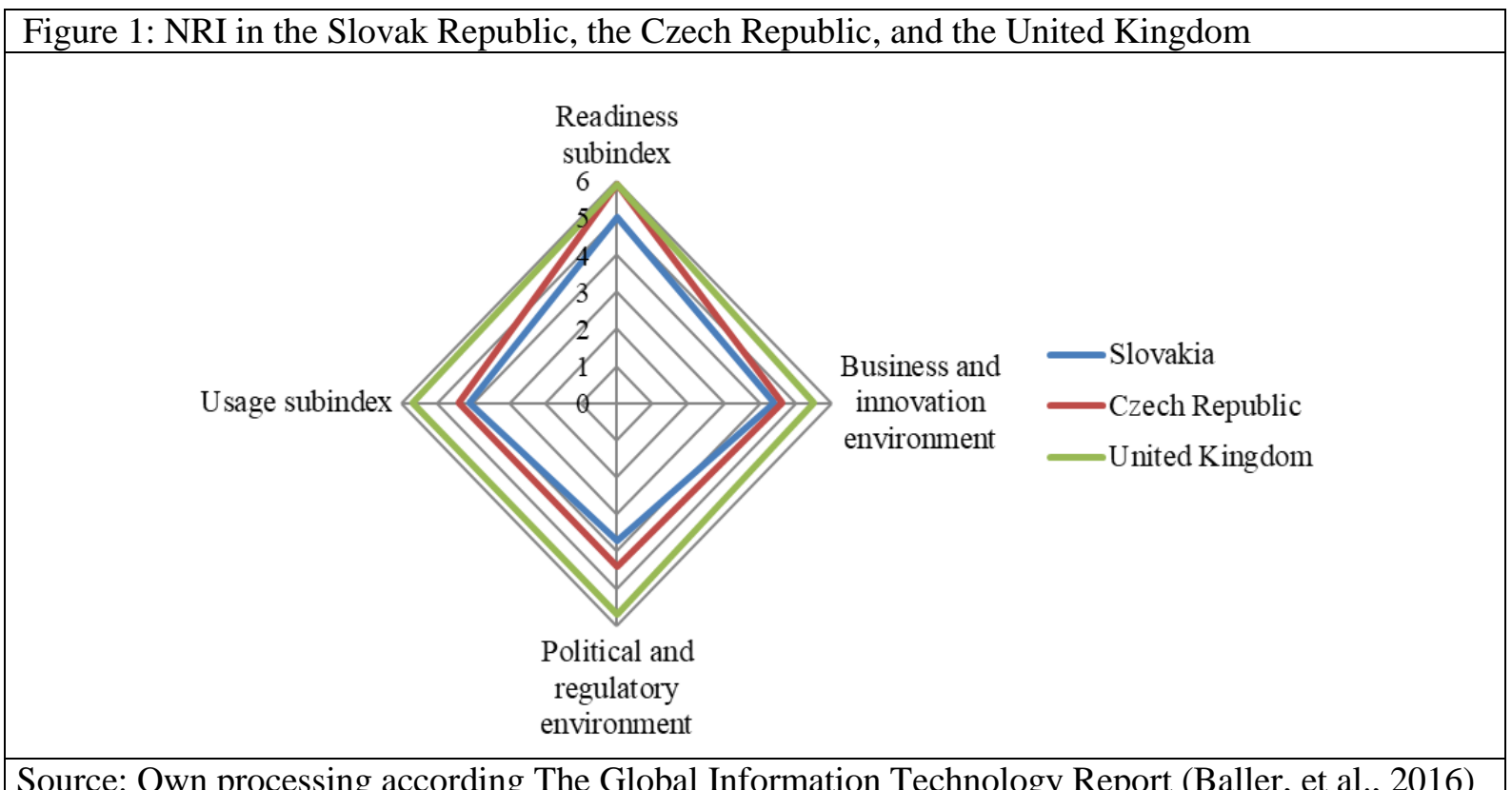

Source: Own processing according The Global Information Technology Report (Baller, et al., 2016)

The state of DESI is prepared by the European Union. (EC, 2020; Úrad vlády ČR, 2019) Figure 2 shows the results of the Member States of the EU in the field of the digital economy and society.

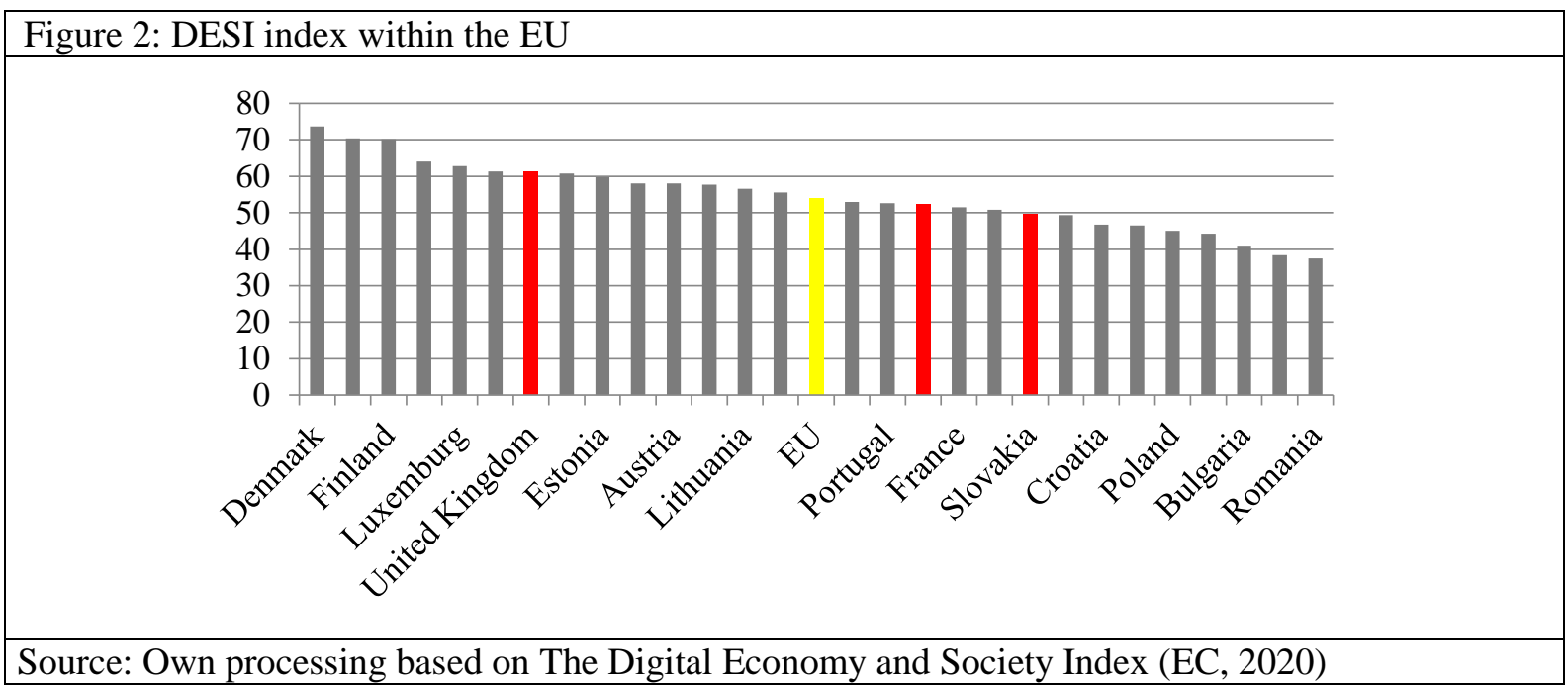

The Slovak Republic ranked 20th in the DESI index for 2018, among all 28 EU Member States, including those member states that performed poorly. Compared to the previous year, the ranking of the Slovak Republic did not change, but its score has increased to 49.5 compared to 2017 when it scored 45.5. The Slovak Republic achieved a lower score compared to the EU average score of 54.

The Czech Republic ranked 17th in the DESI index (2018) with a score of 52.3 and ranked among the countries with average results. In the previous year, the country ranked in the same place, but with a lower score of 49.3. The Czech Republic fell short of the European Union average.

The United Kingdom scored 61.2 in the DESI index (2018) and ranked seventh among the strongperforming countries. The country has improved its score and maintained its position compared to the previous year's score of 58.6. In terms of scores, the country exceeded the European Union average. The UK is among a group of countries with strong results and has achieved the highest ranking in the Human Capital category.

The Czech Republic achieved its highest rating in the category of Human Capital and in the category of Integration of digital technologies, where it ranked 13th. The best results were achieved by the Slovak 
Republic in the Human Capital category and in the Internet Use category, where it ranked 16th. (EC, 2019)

\subsection{Comparison in the field of Digital Transformation Scoreboards}

The aim of the Digital Transformation Scoreboard (DTS) is to monitor the transformation of industry and businesses in the area of digitization and the use of modern technologies. In addition to the evaluation of enterprises, DTS also focuses on the concepts of the implementation of the IoT of individual countries, or some countries have the protocols of the Internet of Things embedded in their Concept for Industry 4.0. The progress made by the member states of the EU in integrating digital technology to better inform and aid national policymakers and industry stakeholders in moving forward. Reflects DTS. The rating of the seven DTS areas is shown in Figure 3. (EC, 2018)

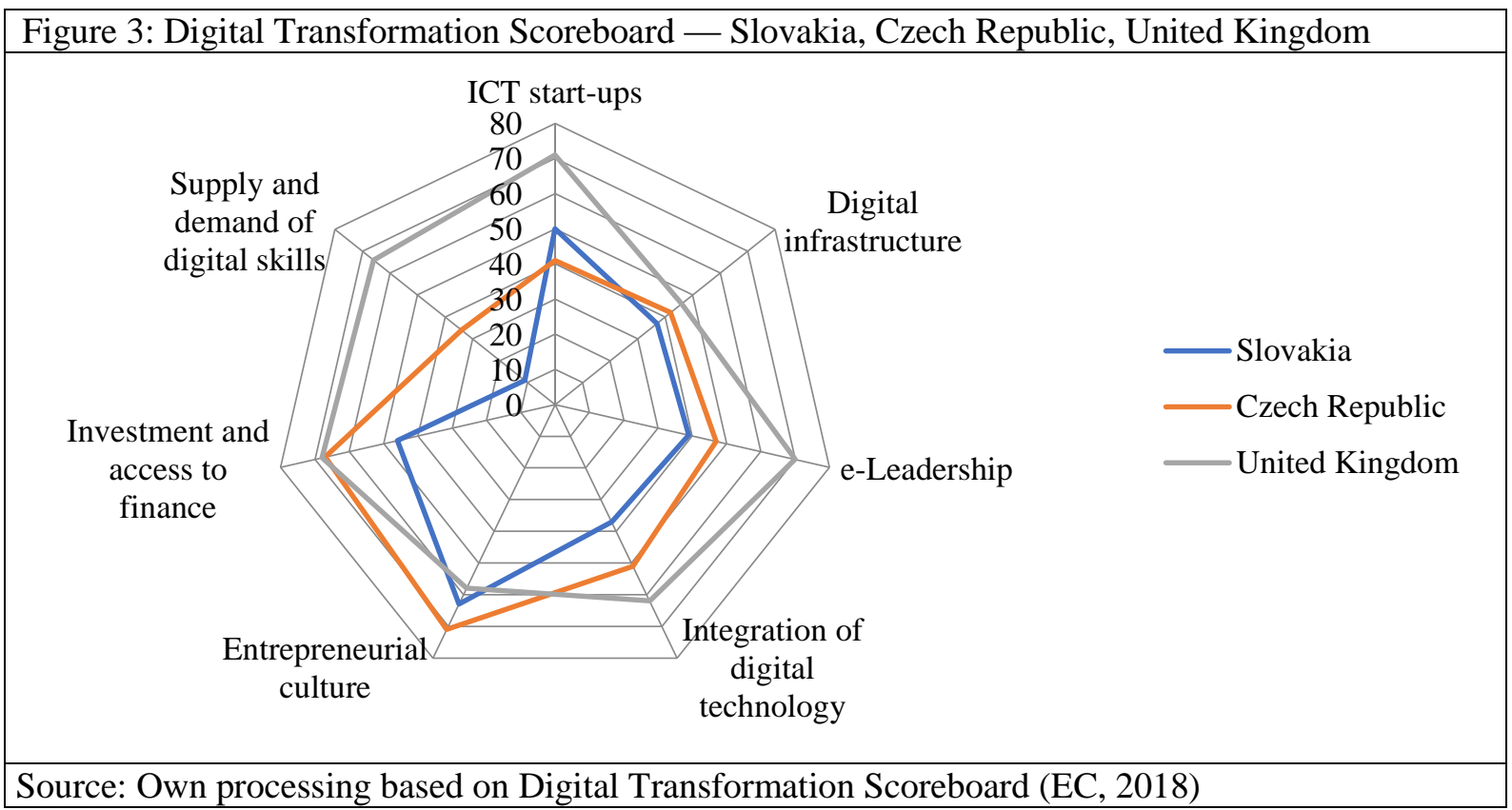

The Slovak Republic lags significantly behind the European Union average in almost all areas assessed using the DTS. In only two of the seven areas has Slovakia exceeded the European Union average. The country ranked best in the field of Startup Evaluation in the ICT sector and in the areas of Investment and Access to Finance (where it surpassed the EU average). (Probst, 2018) The Czech Republic in the DTS, like the Slovak Republic, lags behind the average within the EU, which it managed to overcome in only three evaluated areas. The country ranked best in Investment and Access to Finance and Digital Transformation, where it surpassed the European average. It ranked worst in its assessment in the areas for Supply and Demand for Digital Skills and e-Leadership for Digital Transformation.

In a comparison with the Slovak Republic and the Czech Republic, the United Kingdom exceeded the European Union average in five areas. The worst-ranked areas from the UK perspective were Business Culture and Digital Infrastructure. The country placed best in the evaluation of the Startup area in the ICT sector and in the area of Investment and Access to Finance. (Probst, 2018) Within the selected countries, the UK achieved the best results in the DTS assessment, with the European Union average outperforming in the five areas evaluated. The Czech Republic exceeded the European Union average in the three areas evaluated. Among the selected countries, the worst results were achieved by the Slovak Republic, which exceeded the European Union average in only two areas.

\section{Conclusion}

The Internet of Things has many advantages but also some disadvantages. Among the main advantages of the IoT are, for example, increased efficiency, transparency, quality of activities and the reduction of human intervention, easier access to information, more efficient communication, more time and costefficient data transfer, and process automation. On the other hand, there are also some disadvantages, of which the most feared is the creation of a negative impact on employment, the reliability of IoT devices, the lack of compatibility of devices from different manufacturers, and the protection of confidential or important information. 
Global and local changes in the business environment, increasing pressure to increase productivity, production efficiency, process optimization, and an overall reduction of energy consumption. If this is in line with the Industry 4.0 concept, it can have both positive and negative impacts on businesses. (Buganova \& Simickova, 2020)

In the Slovak and Czech republics, the application of IoT in industry and households, is rapidly spreading. Examples from the United Kingdom are worth noting.

Within the European Union, the Slovak Republic scores below the DESI index and the Digital Transformation Table but its results improve every year. It is also important for the state to understand the importance and benefits of the IoT and to support its implementation. The Internet of Things conceals a revolutionary instrument through which the Slovak Republic can gain a competitive advantage in both the European and world markets. However, the Slovak Republic needs to strive to raise awareness among Slovak companies about the benefits and potential of the IoT and to promote modern and innovative technologies. Direct data transfer without human intervention improves accuracy, eliminates possible errors, and especially saves human work. Many IoT devices are already commonplace. Devices communicate with each other, with the user as well as with diverse applications. Most importantly, they will make life easier by offering more conveniences and useful solutions to citizens. Finally, they will generate income for those who prove to be pioneers in various IoT segments in the markets.

\section{Acknowledgments}

This paper was supported by project KEGA 043ZU-4/2019 and VEGA 1/0755/18.

\section{References}

Andreev, S., Dobre, C., \& Misra, P. (2019). The Internet of Things and Sensor Networks. IEEE Communications Magazine, Volume 57, Issue 12, pp. 64-64.

Baller, S., Dutta, S., \& Lanvin, B. (2016). The Global Information Technology Report 2016, Innovating in the Digital Economy, The World Economic Forum, 289 p.

Barta, D. (2015). Metodika Konceptu inteligentních měst [Methodology of the Smart Cities Concept]. Ministerstvo pro místní rozvoj. https://www.dotaceeu.cz/getmedia/9c597c78-8651-43a8-8d94-bc9f19da74c5/TB930MMR001_Metodikakonceptu-Inteligentnich-mest-2015.pdf>.

Breene, K. (2016). What is 'networked readiness' and why does it matter? World Economic Forum. Retrieved from: https://www.weforum.org/agenda/2016/07/what-is-networked-readiness-and-why-does-it-matter

Buganova, K., Simickova, J. (2020). Increasing the competitiveness of enterprises through the implementation of risk management in the context of the Industry 4.0 concept. International Scientific Conference on the Impact of Industry 4.0 on Job Creation, T. Teplice, Slovakia, 2019, pp. 79-86.

Digital Goals (2020). Internet Of Things And Mobile-Connected Smart Objects. Retrieved from: https://tinyurl.com/yyg7fo8y

European Commission (2018). Digital Transformation Scoreboard. 2018. Retrieved from: https://ec.europa.eu/growth/toolsdatabases/dem/monitor/scoreboard

European Commission (2019, January 26). Digital Economy and Society index 2018 Country Report United Kingdom. Retrieved from: http://ec.europa.eu/information_society/newsroom

European Commission (2020). The Digital Economy and Society Index (DESI) 2019. Retrieved from: https://ec.europa.eu/digital-single-market/en/desi

Gartner (2019, December 8). Internet of Things. Retrieved from: https://www.gartner.com it-glossary/internet-of-things

Gasova, K., Stofkova, K. (2017). Government as a quality improvement tool for citizens' services. Transcom, Procedia Engineering 192, pp.225 - 230 .

Grabowska, S. (2020). Smart factories in the age of Industry 4.0. Management systems in production engineering, Vol. 28. Is. 2, pp. 90-96.

Hurst, A. (2018). The UK's current smart city developments were examined. Information Age. Retrieved from: https://www.information-age.com/the-uks-current-smart-city-developments-examined-123474013

Chcemsmartmesto (2019, January 15). Aj vaše mesto môže byt' smart [Your city can also be smart]. Retrieved from: https://www.chcemsmartmesto.sk/>.

IndexMundi (2019, March 15). Slovakia GDP - composition by sector. Retrieved from: https://www.indexmundi.com/slovakia/gdp_composition_by_sector.html>.

Mayor of London (2019, January 23). Smarter London Together. Retrieved from: https:// www.london.gov.uk/what-wedo/business-and-economy/supporting-londons-sectors/smart-london/smarter-londontogether?fbclid=IwAR0Zr6aTjWjDqp9hVC9wJRbvGsVasK0RXm DwPgEvwW5m WU67AKaP3AY2Q-I 
Ministerstvo prumyslu a obchodu ČR (2020, March 10). Analýza vývoje ekonomiky ČR za rok 2018 [Analysis of the development of the Czech economy in 2018]. Retrieved from: https://www.mpo.cz/cz/rozcestnik/analyticke-materialy-astatistiky/analyticke-materialy/analyza-vyvoje-ekonomiky-craduben-2019--245303/

Ministerstvo zahraničních vecí SR (2019, January 22). Ekonomická informácia o teritóriu Spojené král'ovstvo Vel'kej Británie a Severného Írska [Economic information on the territory of the United Kingdom of Great Britain and Northern Ireland]. Retrieved from: https://www.mzv.sk/documents/1146809/620840/Spojené+král'ovstvo++ekonomické+informácie+o+teritóriu +2018

NetApp (2019, March 15). What Is Big Data? Retrieved from: https://www. netapp.com/us/info/what-is-big-data.aspx Nitra Smart City (2019, March 15). Retrieved from: https://www.nitrasmart.sk

Pohanka, P. (2019, January 10). Internet věcí. [Internet of Things] Retrieved from: http:// i2ot.eu/internet-of-things

Probst, L., Lefebvre, V., Martinez-Diaz, Ch., Bohn, N.U., Klitou, D., Conrads, J. (2018). Digital Transformation Scoreboard 2018: EU businesses go digital: Opportunities, outcomes, and uptake. European Commission. Luxembourg: Publications Office of the European Union, $137 \mathrm{p}$.

Smart Prague (2019, January 22). Projekty Smart Prague [Projects Smart Prague].Retrieved from: https://smartprague.eu/projekty

Soltes, V., Misik, J., Kubas, J., \& Stofkova, Z. (2016). Education in an information society. In: INTED 2016 Proceedings, Valencia, IATED Academy, pp. 4418-4424.

Statista (2019, March 15). Smart Home. Retrieved from: https://www.statista.com/outlook

Statista (2020, March 10). Distribution of employment by economic sector from 2009 to 2019. Retrieved from: https://www.statista.com/statistics/378343/ employment-by-economic-sector

Stofkova, Z. \& Hraskova, D. (2017). Digital skills in the period of the digital economy. In: International Scientific Conference on Marketing Identity: Smolenice, Slovakia, Univ Ss Cyril \& Methodius Trnava, Marketing Identity, pp. $417-$ 425.

Technologies. In: ICERI 2014 Proceedings Seville, IATED Academy, pp. 1969-1974.

Technopedia (2019, March 15). Big Data. Retrieved from: https://www.techopedia. com/definition/27745/big-data Úřad vlády ČR (2019, January 26). DESI Index: ČR si skvěle vede v e-commerce a zlepšuje e-government: The Czech Republic is doing great in e-commerce and is improving e-government]. Retrieved from: https://www.digiczech.eu/desiindex-cr-si-skvele-vede-v-e-commerce-a-zlepsuje-e-government

Wong, W. G. (2012). What's The Difference Between IPv4 and IPv6? In: Electronic Design. Retrieved from: https://www.electronicdesign.com/embedded/whats-difference-between-ipv4-and-ipv6

Yost, S. (2019, January 15). The Five Stages of IoT. Retrieved from: https://www.bsquare.com/blog/the-five-stage-iotmaturity-model 